\title{
Group adjectives*
}

\author{
Bjarne Ørsnes and Stella Markantonatou \\ Copenhagen Business School / Institute for Language \\ and Speech Processing, Athens
}

This paper attempts a comparative syntactic study of group adjectives in Danish, English and Modern Greek. The central problem with group adjectives is to account for the contrast between their seemingly argumental behaviour and their inability to introduce new referents into the discourse. We propose a novel analysis whereby group adjectives form a weakly lexical structure with their head noun and modify the first argument of the argument structure of the head noun while the argument itself remains unexpressed. If this analysis is right, it lends support to the representation of argument structure as a level which is simultaneously distinct from the representation of syntactic valency and participates in valency saturation phenomena. The framework is that of Head-Driven Phrase Structure Grammar (HPSG).

Keywords: Danish/Modern Greek adjectives, group adjectives, HPSG, argument/adjunct-distinction, argument structure, deverbal nominals

\section{Introduction}

In this paper we draw on data from three different languages: English, Danish and Modern Greek. We aim to show that group adjectives, despite some variation, demonstrate strikingly similar syntactic behaviour across the three languages we investigate.

Group adjectives are denominal adjectives derived from place names or names of professions and form a subpart of what is commonly referred to as relational adjectives (Levi 1978). Here we draw on English to exemplify these characteristics of group adjectives but the same properties hold across the three languages we study in this paper. ${ }^{1}$ Gross characteristics of relational adjectives are (Ralli \& Stavrou 1998): 
1. they do not occur predicatively (1)

2. they do not allow modification (2) (but see Section 4.1.3)

3. they cannot be coordinated with other adjectives (3) (but see endnote 8)

4. they cannot be separated from their head (4) (but see Section 4.1.3)

(1) $[\mathrm{EN}]$ the invasion is american ${ }^{2}$

(2) $[\mathrm{EN}]$ *the very american invasion

(3) $[\mathrm{EN}]{ }^{\star}$ the sudden and american invasion

(4) $[\mathrm{EN}]$ *the american sudden invasion

Note that all group adjectives are ambiguous between a group reading and a qualitative reading. All starred examples of group adjectives in this paper are intended to apply to the reading as a group adjective and not as a qualitative adjective. The group reading entails that some people of the kind described by the adjective are involved in the event related with the nominal. The qualitative reading assigns some quality to the nominal. Example (2) is impossible on a reading of american as a group adjective but it is possible on the interpretation of american as American-like or typical American. On the group reading the invasion has to be made by America or Americans to be true while this does not hold for the qualitative reading (Giorgi \& Longobardi 1989).

Group adjectives have been characterised as a peculiar sort of adjective which behaves like an NP, mainly in that they seem to establish semantic case relations with a deverbal noun (Grimshaw 1990) and even introduce new entities into the discourse (Giorgi \& Longobardi 1991). And yet group adjectives fail to behave like NPs in crucial respects, e.g. in their inability to bind anaphors.

In this paper we show that group adjectives are indeed modificational adjectives and not NPs of a peculiar sort. Contrary to NPs, group adjectives do not denote entities and derive their peculiar morpho-syntactic behaviour from the fact that they add restrictions to the first argument in the argument structure list of the head noun (rather than modifying the head noun itself) and the fact that they fail to project adjectival phrases. In this way we attempt to spell out in considerable detail what it means for an adjunct to identify an argument position (Grimshaw 1990).

To support our claims we explore the peculiar interaction of group adjectives with binding phenomena. In order to account for the relevant data we propose a novel treatment of overt and covert anaphoric items which appears to be parametric across languages.

The paper is organized as follows: In Section 2 we discuss the data which 
support the claim that group adjectives establish semantic case relationships and seem to be syntactically related to argument structure. In Section 3 we discuss previous accounts of group adjectives and we show how these accounts are either empirically or theoretically unsatisfactory. In Section 4 we discuss the syntactic identity of the combination of group adjective and deverbal nominal, specifically we address the issue whether it is a syntactic or a lexical construct. In Section 6 we discuss the interaction of group adjectives with binding phenomena. In Section 7 we sketch an account of group adjectives within the framework of Head-Driven Phrase Structure Grammar. The purpose of this section is to indicate the theoretical implications of our analysis for any linguistic framework and we believe that the account can be formalized within other linguistic frameworks as well.

\section{The argument-like behaviour of group adjectives}

In this section we will present and discuss the data which have led several researchers to the conclusion that group adjectives have an argumental function in the NPs in which they occur.

\subsection{The distribution of group adjectives}

Group adjectives only occur with deverbal/picture-nouns, or put differently, the adjectives under consideration only acquire the group reading in conjunction with the mentioned nominals.

The construction [group adjective+deverbal noun] is quite productive across the three languages as corpus search reveals. In order to give a measure of the productivity of the construction, we append an indicative list of nouns combining with group adjectives retrieved from the ILSP Corpus of Modern Greek. Their translations into English and Danish can combine with group adjectives across the three languages studied here.

anadiplosi/withdrawal/tilbagetrckning, anamiksi/involvement/engagement, antidrasi/ reaction/reaktion, antistasi/resistance/modstand, apagorefsi/prohibition/forbud, apantisi/ answer/svar, apili/threat/trussel, apopsi/view, opinion/mening, apofasi/decision/beslutning, anakinosi/announcement/annoncering, arnisi/refusal/afvisning, diekdikisi/claim/påstand, ekviasmos/blackmail/afpresning, ependisi/investment/investering, epidioksi/pursuit/ efterstrcebelse, erevna/investigation/undersøgelse, ishirismos/claim/påstand, katapiesi/oppression/undertrykkelse, katohi/occupation/besæettelse, periorismos/constraint/begransning, 
piesi/pressure/pres, prospathia/effort, attempt/bestrebelse, prostasia/protection/beskyttelse, metarithmisi/reform/reform, prosklisi/invitation/invitation, protasi/suggestion/forslag, simetohi/participation/deltagelse, shediasmos/planning/planloegning, sindromi/help/hjelp, thelisi/will/vilje, ipopsia/suspicion/mistanke, ipostiriksi/support/støtte, ipotimisi/underestimation/undervurdering

We will follow Grimshaw (1990) in distinguishing among complex event nominals, simple event nominals and result ones. The latter are not supposed to receive an eventive interpretation. This distinction is relevant for the distribution of group adjectives in the three languages discussed here. In Danish and English group adjectives can combine with complex event/simple event nominals (5), (7) as well as with result nominals (6), (8).

(5) $[\mathrm{DA}]$ den græske undersøgelse af kandidaterne 'the greek examination of the candidates'

(6) $[\mathrm{DA}]$ den græske beslutning 'the greek decision'

(7) $[\mathrm{EN}]$ the english examination of the candidates

(8) $[\mathrm{EN}]$ the greek decision

More details must be given about the distribution of group adjectives in Modern Greek. Group adjectives can freely combine with result nominals (9).

(9) [GR] i eliniki anakinosi itan safis

'the greek announcement was clear'

On the other hand, structures consisting of group adjectives and complex event nominalisations are not acceptable in Modern Greek (10). ${ }^{3}$ Actually, because of the contrast between (9) and (10), it has been claimed that group adjectives combine with non-eventive deverbal nominals only (Alexiadou \& Stavrou 1998, Alexiadou 2001).

(10) [GR] *i eliniki eksetasi ton ipopsifion 'the greek examination of the candidates'

It is notable, however, that the picture which emerges from the data is more complicated. Below we list data retrieved from the ILSP Corpus (http://www.xanthi.ilsp.gr/corpus/) where group adjectives combine with simple event nominalisations (11).

[ILSP CORPUS 99173]

(11) $[\mathrm{GR}]$...idikoteres drasis kata tomis, gia tis opies tha mporouse na ksekinisi i eliniki proetimasia 
'...special actions according to sectors, which the greek preparation could start off

Furthermore, group adjectives can combine with event nominalisations derived from unaccusative predicates. The nominal metanastefsi "emigration" has been classified as unaccusative in Markantonatou (1995) and Alexiadou \& Stavrou (1998) and yet it may occur with group adjectives as in (12) below.

(12) [GR] etsi arhise i evraiki metanastefsi stin Evropi

'This is how the jewish emigration to Europe has started.'

What this data suggests is that group adjectives can combine with eventive nominals in Modern Greek albeit only with simple event ones.

Summarizing, in English and Danish group adjectives occur with all aspectually defined kinds of deverbal nominal while in Modern Greek they combine with simple event and result denoting nominals only.

In this paper we assume that the distribution of group adjectives is related to the level of representation which is called "argument structure" (while the differences in distribution are related to language dependent structural issues concerning the DP). We thus assume that all deverbal nominals are endowed with an argument structure but they differ in their ability to take obligatory arguments (Sag \& Godard 1994). ${ }^{4}$ In that, we are in agreement with recent work by Alexiadou (Alexiadou 2001) who, working within the Minimalist Program, claims that all deverbal nominals are endowed with an argument structure but they differ in the number of functional projections which rule the syntactic realisation of logical arguments.

\subsection{The interpretation of group adjectives}

What mainly sets group adjectives apart from other adjectives is that they seem to manifest semantic case relations. In the examples (13) through (15) below, the group adjectives identify the agent argument of the nominalization, which naturally corresponds to the subject argument of the related active verbal predicate. In this sense group adjectives seem to behave like arguments rather than like adjuncts.

(13) $[\mathrm{DA}]$ den amerikanske beslutning 'the american decision'

(14) $[\mathrm{EN}]$ the american decision

(15) [GR] i amerikaniki izvoli

'the american invasion' 
As noted above a "group adjective" is a particular use of the adjectives under consideration which are systematically ambiguous between a qualitative reading and a reading as a group adjective. The reading as a group adjective, however, is generally only available in attributive use. The postcopular position brings out the qualitative reading (but see endnote 4):

(16) $[\mathrm{EN}]$ The decision is american

Group adjectives as illustrated in (13) through (15) allude to groups of people sharing some salient property such as nationality or origin. Presumably the specific interpretation of group adjectives is due to lexical semantic and contextual factors. The adjective itself alludes to a certain nationality while the group reading is due to selectional restrictions imposed by the deverbal nominal on its first argument. In the case of decision the decision maker is commonly taken to be human and this is all we know about the agent of decision. We may assume that american in (14) points to a certain authority associated with the decision. Likewise the amerikaniki "american" in (15) may be interpreted as pointing to the army, but these are inferences which are not licensed by the adjective itself. As a matter of fact even the plurality associated with group adjectives may be due to contextual factors. An american decision e.g. may be made by the American president alone. Certain adjectives which allude to a profession rather than a nationality as exemplified in (17) and (18) below occur in a use similar to that of group adjectives.

(17) $[\mathrm{EN}]$ the presidential decision

(18) $[\mathrm{EN}]$ a papal appeal

These adjectives differ from standard group adjectives such as american in not having the same kind of vague reference to a group but again this may be due to contextual inferences since we know that there is only one president and only one pope and otherwise they exhibit the same syntactic behaviour as group adjectives alluding to nationalities. As we will show below the specific interpretation of group adjectives follows from our analysis in a straightforward manner.

As noted, it is a notable characteristic of group adjectives that, when modifying deverbal nominals, they identify the semantic argument which normally surfaces as the subject of the active verb related to the nominal.

(19) [EN] Denmark's invasion by the Germans

(20) [EN] ${ }^{\star}$ The danish invasion by the Germans 
In (19) we have a so-called passive nominal where the pronominal genitive identifies the theme argument - the canonical object of the corresponding active verb - and, the oblique by-phrase identifies the agent - the canonical subject of the corresponding active verb. In (20), however, it is not possible to interpret the adjective as the theme-argument. Such an interpretation is available only in conjunction with nominalizations of unaccusative verbs as in (21) (Markantonatou 1995). ${ }^{5}$

(21) [GR] i proedriki afiksi

'the presidential arrival'

Rare cases where the group adjective identifies the theme role (and, equivalently, the object) of a transitive verb are, however, attested, e.g. in Grimshaw (1990) who gives the following example:

\section{(22) $[\mathrm{EN}]$ the central-american invasion}

There seems to be some disagreement as to the possibility of examples such as (22) above. Kayne (1984) assumes that the adjective in (22) can not be interpreted as a theme and uses this as a cornerstone in his discussion of subject/ object-asymmetries in English. Giorgi \& Longobardi (1989) argue that group adjectives (or referential adjectives in their terminology) in Italian can only be associated with an external semantic function and use this in their argumentation for a trace-based analysis of group adjectives. Our informants consider examples such as (22) ambiguous with a tendency to interpret central-american as an agentive argument. In any case the example in (22) does not seem to be productive. Our informants interpret the example in (23) as an invasion made by Poland and not as an invasion of Poland even though both readings should be available viz-à-viz (22).

\section{(23) $[\mathrm{EN}]$ the polish invasion}

To the extent that (22) is possible on a theme reading of the group adjective, we assume that it is a lexicalised construct which - possibly due to contextual factors - may differ in interpretation from canonical uses of group adjectives.

Summing up what has been said so far, group adjectives in all the three languages we examine, are canonically associated with the subject argument of the verbal predicate related to the deverbal nominal the group adjective applies to. This holds irrespective of the thematic role assigned to the verbal subject argument. It seems that the conditions which apply to the syntax of group adjectives do not make reference to thematic roles. However, the fact is that the 
thematic role agent is canonically realised as the subject (of an active verb) in the languages discussed here (as in all nominative-accusative languages). Consequently, it is very often the case that the group adjective is interpreted as the agent/instigator of the event/result referred to by the nominal. We will refer to this as the "canonical" interpretation of group adjectives.

Let us now combine the distribution facts presented in Section 2.1 and the interpretation facts presented here (Section 2.2). Two conditions seem to rule the distribution of group adjectives so far:

1. the group adjective is related to the subject argument of the corresponding active verb predicate

2. the group adjective occurs with nominals which allow for referential expressions (DPs) related with the corresponding verbal subject and which are marked with the genitive case

As regards the second point above, group adjectives in English and Danish occur with complex event nominalizations which allow a Saxon genitive (John's examination of the candidates) but not with complex event ones which allow a by-PP (the examination of the candidates by John). Actually, these are two different types of nominalisation, the first one termed "transitive nominalizations" and the second "intransitive nominalizations" (Chomsky 1970). Modern Greek does not allow the first type of complex event nominalisation because it does not allow anything like a Saxon genitive (Alexiadou 2001). Actually, the MG DP cannot contain more than one DP in the genitive case (Horrocks \& Stavrou 1987). Simple event/result nominalizations occur in all the three languages and allow thematic DPs in the genitive case.

Those two conditions also capture the fact that English allows for a Saxon genitive which cannot be related with a group adjective; (25) fails the first condition.

(24) [EN] Denmark's invasion by the Martians

(25) $[\mathrm{EN}]$ *the danish invasion by the Martians

In the remainder of this paper we will formalise these constraints and explain the asymmetries observed so far by making reference to concepts such as argument structure and adjectival modification.

\subsection{Syntactic reflexes of group adjectives}

Apart from manifesting semantic case relations group adjectives participate in uniqueness phenomena of the kind embodied in the $\theta$-criterion of Government 
and Binding Theory or Function-Argument Biuniqueness of Lexical-Functional Grammar. Uniqueness is thus a typical reflex of argumental behaviour.

(26) $[\mathrm{EN}]{ }^{*}$ the german decision by the Israelis

(27) $[\mathrm{EN}]{ }^{*}$ the german israeli decision

Both (26) and (27) are ruled out on a reading where German and Israeli respectively are interpreted as group adjectives, that is, as identifying the decision makers. The examples are possible only on a non-group reading of the adjectives in question, i.e. where the decision is particularly "German"-like or was made in Germany. The fact that a group adjective can not co-occur with an NP or another group adjective identifying the same logical argument makes clear that group adjectives have access to some level of lexical information that determines argument saturation. Later, we will propose that this is the argument structure level and not the subcategorisation level. In Section 7.2 we will return to a more thorough discussion of this issue.

Furthermore, we will propose that group adjectives are associated with the first argument of the argument structure list (later, we claim that they simply modify it). Our proposal is based on the fact that group adjectives are invariably related to semantic arguments which surface as subjects with the corresponding active verbs, such as the actor of transitive/unergative verbs or the undergoer of unaccusative verbs. This argument-like behaviour of group adjectives seems to suggest that group adjectives are referential entities (in the sense of being entitydenoting, i.e. picking out an entity in discourse (Kolliakou 1999)) and even subject arguments (Giorgi \& Longobardi 1991). However, below, we bring evidence from binding (cf. Section 6 ) that group adjectives are neither referential entities, nor subjects. ${ }^{6}$

\section{Previous accounts of group adjectives}

One of the most prominent discussions of relational adjectives (of which group adjectives form a subgroup) is Levi (1978). Levi's proposal is the first one on the issue but it focuses on the derivation of group adjectives rather than their syntactic function. Levi analyses the combination of a relational adjective and a nominal as an instance of what she terms complex nominals also comprising nominal compounds. Working within a transformational framework she assumes that group adjectives are Ns at deep structure and that they are turned into adjectives by a process of morphological adjectivalization thus accounting 
for pope appeal $\rightarrow$ papal appeal. Levi accounts for the conflicting behaviour of the adjective as both nominal and adjectival by positing different levels of representation and by positing a transformation, which somehow accidentally turns a noun into an adjective. We will show how the facts can be accounted for without positing different levels of representation and category-changes in the syntax. Finally Levi's account has no explanation for the fact that the adjective is canonically interpreted as an agent in combination with a nominalisation based on a transitive verb.

Giorgi \& Longobardi (1991) develop an account which bears much resemblance to the use of group adjectives in Kayne (1984). Giorgi and Longobardi assume that group adjectives are referential expressions (hence the term: referential adjectives) introducing new referents into the universe of discourse and that they discharge a $\theta$-role of the head but never an internal one. In order to establish that the subject is base-generated to the right of the head in Romance they use group adjectives as a corner stone in their argumentation. In Italian, group adjectives can only occur postnominally (28). In prenominal position they acquire a qualitative reading so that the invasion in (29) is described as being typical Italian.

(28) [IT] l'invasione italiana

'the italian invasion'

(29) [IT] *l'italiana invasione

This is expected if the subject is base-generated to the right of the head and if the adjective is incapable of binding an NP-trace resulting from movement to the left. But again the analysis does not explain how an adjective comes to occupy an NP-position and also their analysis crucially relies on the existence of traces.

Grimshaw (1990) analyses group adjectives, prenominal genitives and by-phrases in passives and nominals as a-adjuncts, i.e. adjuncts identifying suppressed argument positions. The notion of an a-adjunct motivates the existence of argumental adjectives in the sense that adjectives are adjuncts par excellence. However, the peculiar interaction between group adjectives and binding phenomena suggests that group adjectives are indeed distinct from the thematic NP-adjuncts discussed in Grimshaw (1990).

Alexiadou \& Stavrou (1998) claim that group adjectives are not thematic at all, rather they are classifier-like adjectives having the role of sub-classifying the denotation of the head noun (p. 109). They base their argumentation on the assumption that group adjectives only combine with (non-eventive) ordinary common nouns in Modern Greek which we have already seen to be questionable 
(cf. the discussion in Section 2.1.). Furthermore, this analysis offers no explanation for the canonical interpretation of group adjectives as agent-like. Firstly, if group adjectives are not related to some kind of argument structure, it is unclear where the agent-interpretation originates. Secondly, if the interpretation of group adjectives is not regulated by some syntactic (a-structure related) principle, there is no reason why they should not also be interpreted as theme-like. On Alexiadou \& Stavrou's analysis, a theme-like interpretation of group adjectives leads to a violation of the Projection Principle because the group adjective appears in a pre-head position and not in the canonical object position after the head. But if the nominal does not support syntactic arguments, the Projection Principle is not operative and so nothing should prevent a theme-like interpretation which, however, is generally not available. Alexiadou \& Stavrou suggest that the adjectival suffix - $i k$ - "absorbs the thematic role" (p. 111) but it remains unclear where this thematic role comes from if the nominal does not support some kind of argument structure.

The analysis in Alexiadou (2001) overcomes these problems in assuming that an argument structure always exists but syntactic realisation of arguments is controlled by functional projections such as tense and aspect. On this analysis the notion of "absorption of a thematic role" needs to be explicated and this is exactly what is attempted in the present analysis even though the linguistic framework is different from the one in Alexiadou (2001).

In short, most researchers agree that group adjectives in one way or another are related to the argument structure of the head noun but it remains obscure exactly what group adjectives do and what kind of syntactic status they have.

\section{The morpho-syntactic status of group adjectives}

In Section 2 we presented the reasons why group adjectives have been thought to have an argument-like function within the NP. In this section we will start building our argumentation against this claim and we will address the problem of the syntactic status of group adjectives. First of all we will explore the possibility that the group adjective forms a compound with its head nominal. Secondly we will discuss whether group adjectives are adjectives at all and, if so, whether the combination of a group adjective and a nominal is a lexical structure transparent to the syntax (a weakly lexical structure) or a fully phrasal structure. Finally we will discuss whether group adjectives present a uniform syntactic behaviour cross-linguistically. 
4.1 Do group adjectives form compounds?

As noted above, Levi (1978) analyses the combination of a group adjective and a deverbal noun as a complex nominal, i.e. as a kind of compound. If we are in fact dealing with a compound the inseparability of the adjective and the head noun and the lack of adverbial modification follow straightforwardly. If we further assume that the group adjective is a kind of nominal argument, the apparent non-referentiality of the adjective (i.e. that it does not denote an entity) and its inability to bind phrasal anaphors is accounted for since nonheads below the word level generally resist reference and are opaque to syntax. This analysis would further explain why predicative adjectives and group adjectives can not coordinate, the former being phrasal. There is, however, much evidence pointing to the conclusion that they are not compounds.

In the following we will discuss each of the languages individually and we will conclude that the formation Group Adjective + Noun is not a compound.

\subsubsection{Danish}

In Danish, nouns with an adjectival premodifier take the article den/det "the" while nouns without adjectival modifiers take the affixal article -en/-et:

(30) $[\mathrm{DA}]$ den store vinflaske 'the big wine bottle'

(31) $[\mathrm{DA}]$ vinflasken wine bottle.DEF

(32) $[\mathrm{DA}]{ }^{\star}$ store vinflasken big wine bottle.DEF

A group adjective with a deverbal noun always takes the definite article den/det "the" like other nouns with adjectival premodification. Thus, this structure does not behave as a compound as regards determiner selection.

(33) $[\mathrm{DA}]$ den amerikanske beslutning 'the american decision'

(34) [DA] *amerikanske beslutningen american decision.DeF

If group adjectives and deverbal nouns form compounds we should expect them to undergo further word formation processes such as compounding and backformation. Since compounding is recursive, a compound may occur as head or non-head in another compound: 
(35)
[DA] hurtiglæsning fast reading
(36) [DA] hurtiglæsningsforsøg fast reading attempt

If however a group adjective and a noun participate in further compounding the scope of the adjective will invariably be the head of the new compound:

(37) [DA] den amerikanske invasion the American invasion

(38) $[\mathrm{DA}]$ den amerikanske invasionsfordømmelse the american invasion condemnation

(38) is only possible on a reading where the adjective applies to fordømmelse "condemnation" and not invasion "invasion". If the group adjective and the noun were a compound we should expect the adjective to apply to invasion also in the new compound.

In Danish, non-heads in compounds may coordinate (39) but a group adjective can not coordinate with a non-head of a compound (40). This is further evidence that the combination of a group adjective and a noun does not form a compound structure in Danish:

[DA] blå- og rødmalingen af stakittet blue and red painting.DEF of the fence

(40) $[\mathrm{DA}]$ *den engelske og amerikanerinvasion the english and american. Noun invasion

Note further that contrary to English the combination of a group adjective and a deverbal noun in Danish is subject to internal modification. The adjective is inflected for definiteness and number, and generally non-heads in compounds are not inflected. Cf. the examples below:

$$
\text { [DA] }
$$
en amerikansk
invasion an american.INDEF.SING invasion
$[\mathrm{DA}]$
den amerikanske invasion the american.DEF.SING invasion

A diagnostic for compoundhood in Danish is the fact that compounds are written as one word and group adjectives are never written as one word with their head noun.

Finally there is interpretative evidence that the group adjective and the 
noun do not form a compound. According to the analysis in Ørsnes (1995), external arguments do incorporate in Danish synthetic compounds, but it is far less common than having internal arguments incorporate. The most usual in synthetic compounding is to have an incorporated theme-argument. As noted above, however, group adjectives are canonically interpreted as agents which means that the alleged compounds containing group adjectives would differ remarkably from other synthetic compounds in having agentive non-heads. And this would leave us to explain why agentive non-heads are generally realized as adjectives and theme-like non-heads as nouns. For English it is furthermore claimed that external arguments can never occur in compounds (Grimshaw 1990 and Selkirk 1982) so the difference between nominal synthetic compounds and those containing group adjectives would be even more remarkable in English.

\subsubsection{English}

English combinations of group adjectives and deverbal nouns do not seem to form compounds either even though the picture is not as clear as in Danish. First of all the majority of English compounds are written in two words just like phrasal constructions, secondly English adjectives do not inflect so there is no morphological difference between adjectives as parts of phrases and as parts of morphological structures as was the case in Danish.

In English, however, the combination of a group adjective and a noun do not seem to be input to further word formation processes. For that reason we hardly encounter any backformations of group adjectives and nouns:

(43) $[\mathrm{EN}]{ }^{*}$ to american invade

(44) $[\mathrm{EN}]$ *to greek decide

The question is whether the group adjective and its head nominal may undergo further compounding as was the case in Danish:

(45) [EN] ?? the american invasion condemnation

The oddity of (45) may be due to the fact that English deverbal nominals do not appear to undergo further compounding as easily as e.g. in Danish. But still the preferred reading of (45) seems to be one where the adjective takes scope over the whole compound and not just over invasion as otherwise expected if american and invasion did indeed form a compound.

Sadler \& Arnold (1994) following Levi (1978) do suggest that group adjectives form compounds with the nouns they combine with. However, this 
formation fails some of the diagnostics for "strong lexicality" according to the terminology introduced in Sadler and Arnold. The first diagnostic concerns coordination. According to Sadler and Arnold, sublexical material can not be coordinated (apart from certain prefixes).

(46) [EN] ${ }^{*}$ Mary un- and re- tied her laces

However, group adjectives do coordinate. (47) is acceptable in English under a collective interpretation. ${ }^{7}$

(47) $[\mathrm{EN}]$ the greek and turkish decision

A second diagnostic is provided by the use of the proform one. Compounds are not transparent to syntactic processes but with group adjective plus noun formations we can have $\mathrm{N}$ or $\mathrm{N}$-bar deletion.

(48) [EN] We heard the english decision about the mad cow disease and the german one.

There is thus evidence that the English formations consisting of a group adjective and a noun are transparent to syntax and consequently they are not compounds.

Finally, the fact that some speakers of English allow the group adjective to bind anaphors suggests that these adjectives are not non-heads of compounds (see Section 6). Lexical structures are opaque to the syntax and consequently sublexical material cannot bind anaphors in the syntax.

\subsubsection{Modern Greek}

Phrasal compounds are attested in Modern Greek (Anastasiadi-Simeonidi 1986, Ralli \& Stavrou 1998). While (49) takes a (nearly) compositional meaning, it is often the case that compositionality does not apply at all (50) (Ralli \& Stavrou 1998, p. 248).

(49) $[\mathrm{GR}]$ i piriniki vomva

'the nuclear bomb'

(50) [GR] i pediki hara the childish joy 'playground'

In this section we follow Ralli \& Stavrou (1998) in claiming that the constructions [relational(group) adjective+noun] are syntactic constructs. The productivity of the phenomenon (see Section 2.1.) seems to suggest that these are 
indeed syntactic constructions. Further evidence is provided by Ralli \& Stavrou (1998) who draw on syntactic evidence such as parentheticals (51), double definiteness (52) and modification (53) by noun-modifying adverbs.

(51) [GR] afti i kineziki -hrisimi, opos fenete- protovoulia 'this chinese, useful as it seems, initiative'

[ILSP CORPUS 220106]

(52) [GR] i epifilaksi i eliniki den ehi tipote to eksofreniko the reservation the greek not has anything the extraordinary 'the greek reservation is not extraordinary'

(53) [GR] afti i kata kirion logon/tipis evropaiki apofasi (i Amerikani ihan ekfrasi antirisis) apetelese ton akrogonieo litho ton prosfaton energion tis epitropis 'this mainly/conventionally european decision (Americans had expressed doubts) has turned out to be the cornerstone of the recent actions of the committee'

Some additional semantic and syntactic evidence in favor of the syntactic nature of these constructs is given below. First of all, the semantics of the [adjective+noun] compounds differs from the semantics of the [group adjective+noun] constructs. The compounds denote objects of a specified type, which can be distinguished from and contrasted with other objects in qualitative terms defined by the overall meaning of the compound. This does not hold for the [group adjective+noun] constructs which simply denote some event/the result of some event involving the entities the group adjective alludes to. This is a major difference which points right to the nature and definition of compounds. [Group adjective+noun] constructs have compositional meanings and do not refer to objects of a specified type. Thus, the american blackmail in (54) is not a kind of blackmail or other object and cannot be used as an answer to the question "what kind of blackmail/object do they ask the assembly to ignore?". It is nothing else but a blackmail made by some Americans. This NP can only be used as an answer to questions such as "which blackmail?" or "the blackmail by whom?".

\section{[ILSP CORPUS 118222]}

(54) [GR] zitoun apo tin sinodo na apsifisi ton amerikaniko ekviasmo uper tou ...

'they ask the assembly to ignore the american blackmail in favor of ...' 
Further support for the argument that syntactic constructs are semantically distinct from compounds is brought by the criterion of equivalent meanings (Bouvier 2000): if the adjective+noun construct has a meaning equivalent to a regular (minimal) structure with an undeniably compositional meaning, then the construct is likely to be syntactic in nature. In (55) the [group adjective+noun] construct and the [noun+NP[gen]] one have equivalent semantics. This is not the case for the compound (56) where the N+NP[gen] construct may mean the decree signed/invented/owned by the president while the group adjective+noun construct means "a kind of decree which must be issued by the president".

(55) $[\mathrm{GR}] \quad \mathrm{i}$ eliniki antistasi $=\mathrm{i}$ antistasi ton Elinon 'the greek resistance $=$ the resistance of the Greeks'

(56) [GR] to proedriko diatagma? to diatagma tou proedrou 'the presidential decree? the decree of the president'

Note that this approach is in consonance with the view in Giannakidou \& Stavrou (1999) that relational adjectives are "classifying" adjectives which "subcategorise" the denotation of the nouns they modify giving rise to a set/superset relation. The special thing about group adjectives is that they do so by "subcategorising" the denotation of one of the logical arguments of the noun, exactly in the way that a referential expression would do: "the decision of the Americans" is a subset of decisions exactly in the way that "an american decision" is on the group adjective reading (and, of course, not on the qualitative reading).

Further evidence in favour of the syntactic nature of the [group adjective+noun] constructs is contributed by uniqueness phenomena. Consider (57) which has been classified as a compound (Anastasiadi-Simeonidi 1986). The [group adjective+noun] compound featuring in (57) is not subject to uniqueness phenomena (58). However, we have already pointed out that, normally, [group adjective+noun] constructs are subject to such phenomena (cf Section 2.3).

(57) $[\mathrm{GR}]$ to proedriko diatagma 'the presidential decree'

(58) [GR] to proedriko diatagma tou C. Stefanopoulou gia themata shetika me tin Pedia

'the presidential decree of C. Stefanopoulos about educational issues' 
Note further that the combination of a group adjective and a nominal is transparent to the syntax in as much as NBAR-deletion is possible (59).

(59) [GR] i amerikaniki apofasi na stamatisoun i mahes kai i antistihi rosiki 'the american decision for the fights to stop and the corresponding russian one'

The discussion above shows that the Modern Greek [adjective+noun] compounds and the group adjective + noun constructs have different syntactic behavior and different semantics. We thus adopt the conclusion of Ralli \& Stavrou (1998) that the Modern Greek [group adjective+noun] constructs are not compounds.

\subsection{What kind of phrase structure?}

We have established that the combination of a group adjective and a nominal is not a compound in all the three languages we examine in this paper. The construction has been shown to be transparent to syntax. In this section we will investigate the exact nature of this syntactic construction, but before doing so we will present some facts about NP structure in the three languages under consideration.

In both English and Danish, adjectives are prenominal modifiers and both English and Danish have NPs with prenominal genitives which in many respects seem to pattern with subject arguments. Agentive phrases may further be realized as postnominal prepositional phrases which, however, are very rare in Danish. Object-like arguments are generally realized as oblique prepositional phrases with the marker of/af. Modern Greek also has prenominal adjectives, but Modern Greek does not have prenominal genitives, instead we find oblique prepositional phrases normally occurring postnominally. Object-like arguments are realized as genitives which generally occur postnominally, but which may occur prenominally in an emphatic use (Horrocks \& Stavrou 1986).

\subsubsection{Group adjectives are adjectives}

Group adjectives do not pattern with arguments of nominals. In English and Danish the subject-like argument of a nominalisation is realized in the genitive case (60), (61) or as an oblique prepositional phrase (62), (63), which, as noted, is very rare in Danish. In Modern Greek it is realized as an oblique prepositional phrase (64) because Modern Greek allows for only one NP in the genitive case within an NP (Horrocks \& Stavrou 1986): 
(60) [DA] troppernes ødelæggelse af byen the troops.gen destruction of the city

(61) $[\mathrm{EN}]$ the troops' destruction of the city

(62) [DA] byens ødelæggelse ved tropperne 'the city's destruction by the troops'

(63) $[\mathrm{EN}]$ the destruction of the city by the troops

(64) [GR] i katastrofi tis polis apo to strato

Group adjectives do pattern with the ADJ+N construction in terms of word order and concord phenomena (where such phenomena are observed) where the adjective is a premodifying adjunct. In Modern Greek, for instance, adjectives normally precede nouns and agree with them in gender, number and case.

$$
\begin{array}{ccccc}
\text { (65) } & {[\mathrm{GR}]} & \mathrm{i} \text { eliniki } & \text { antidrasi } \\
\text { the } & \text { greek.FEM.SG.NOM reaction.FEM.SG.NOM } \\
\text { (66) } & {[\mathrm{GR}]} & { }^{*} \mathrm{i} & \text { elinikous } & \text { antidrasi } \\
& & \text { the } & \text { greek.MASC.PL.ACC reaction.FEM.SG.NOM }
\end{array}
$$

In Danish, adjectives also precede their nouns and agree with them in gender, number and definiteness:

$$
\begin{gathered}
\text { [DA] en amerikansk beslutning } \\
\text { an american.sG.INDEF.COMM decision }
\end{gathered}
$$
den amerikanske beslutning the american.SG.DEF.COMM decision

On these grounds we conclude that group adjectives are indeed adjectives and not a special kind of nominal. In the following we proceed to investigate what kind of syntactic structure they form with their head noun.

\subsubsection{The syntactic structure of group adjectives and their head nominal} We concluded in Section 4.1 that group adjectives do not form compounds with their head nominal. In this section we will argue that group adjectives form weakly lexical structures with their head nominal, i.e. they constitute a structure with lexical features but still transparent to the syntax. In that, we follow work recently published on English (Sadler \& Arnold 1994) and Modern Greek (Ralli \& Stavrou 1998).

Sadler \& Arnold (1994) argue that English prenominal adjectives which are not part of compound structures are small constructions, i.e. weakly lexical 
structures containing an $\mathrm{A}^{0}$ and an $\mathrm{N}^{0}$. The special thing about this construction is that it shares many features with phrasal structures and so is transparent to the syntax. It is, however, lexical in the sense that prenominal adjectives do not take any complements and are subject to special interpretative constraints. Prenominal adjectives are associated with individual level properties while postnominal adjectives are associated with stage level properties (p. 102).

In general there is no reason to assume that prenominal adjectives in Danish and in Modern Greek are As and not APs (Ralli \& Stavrou 1998). Both Danish and Modern Greek allow for complement-taking adjectives in prenominal position. Note, however, that prenominal APs are right-headed contrary to postnominal APs.

(69) [DA] en af bestyrelsen uafhængig direktør an of the council independent director 'a director independent of the council'

(70) $[\mathrm{GR}]$ enas sigouros gia ton eafto tou andras a confident about the self his man 'a man confident about himself'

However, as noted several times, there is no evidence that group adjectives project phrases. On the contrary there is evidence that they form lexical structures with their head nominal: they cannot be separated from their head, they cannot denote entities and they are very restricted in their potential for modification. In the theory of non-projecting words in Toivonen (2001), nonprojecting lexical items must adjoin to heads while projecting lexical items adjoin to phrases. We thus assume that group adjectives, which form weakly lexical structures, are $\mathrm{A}^{0}$ which adjoin to an $\mathrm{N}^{0}$ to form an $\mathrm{N}^{0}$. The valency features of the head nominal are inherited onto the lexical structure as in all adjunction structures. This accounts for the fact that group adjectives may adjoin to complement-taking nominals (72), (74):

(71) $[\mathrm{DA}]$ den græske beslutning 'the greek decision'

(72) [DA] den græske undersøgelse af kandidaterne 'the greek examination of the candidates'

(73) $[\mathrm{EN}]$ the greek decision

(74) $[\mathrm{EN}]$ the english examination of the candidates 


\section{Phrase structure and argument structure}

As we discuss in Sections 2.2 and 6, there are good reasons to assume that group adjectives have access to the argument structure of the head nominal: uniqueness and binding facts as well as the constraints ruling the group adjective distribution point to this conclusion. This analysis matches well with an analysis where group adjectives and head nominals form weakly lexical structures. Only lexical items are endowed with an argument structure and, since we have a lexical adjunction structure, the group adjective may add a restriction to an argument of the head nominal. Actually, this is the central proposal of this paper.

This proposal accounts for the cluster of properties of group adjectives uncovered in the earlier sections. The lexical nature of the construct allows for an argumental interpretation of the adjective thus explicating what it means to "identify a suppressed argument position" (Grimshaw 1990) or to have "absorbed a $\theta$-role" (Alexiadou 2001). Furthermore, it accounts for the fact that group adjectives are not entity-denoting and that they exhibit lexical behaviour in as much as they cannot be separated form their head nominal either by intervening adjectives or a copula verb.

The proposal also explains coordination facts. As noted above group adjectives do not coordinate with other adjectives:

(75) $[\mathrm{EN}]$ *the sudden and american invasion

(76) $[\mathrm{DA}]{ }^{\star}$ den kloge og græske beslutning the wise and greek decision

In Modern Greek and Danish this is actually predicted. Group adjectives are lexical while other prenominal adjectives are phrasal and so they fail to coordinate. In English however all prenominal adjectives are claimed to be lexical (Sadler \& Arnold 1994) and so coordination cannot fail on syntactic grounds. The failure can, however, be explained on semantic grounds.

The adjective sudden predicates a quality of the head noun invasion. The adjective american, however, predicates a quality of one of the arguments of the head noun and not of the head noun itself. On the assumption that adjectives coordinate to yield one restriction set with one modificational target, the coordination above is ruled out since the two adjectives have different modification targets, the index of the head noun and the index of the "subject" argument, respectively.

The proposal still faces the possibility of proforms and NBAR deletion in 
conjunction with structures containing group adjectives and nominals as illustrated below:

(77) [DA ] den tyske beslutning om at deltage er klogere end den græske ditto 'the german decision to participate is wiser than the greek one'

(78) [DA] den tyske henvendelse til Kommissionen kom før den græske 'the german address to the Commission arrived before the greek one'

(79) [GR ] i agliki apofasi gia ta aftokinita anakinothike mazi me tin germaniki

'the English decision about the vehicles was announced together with the German one'

(80) [EN] the danish application for membership arrived before the greek one

Sadler \& Arnold (1994) claim that the standard test of inserting the proform one which is taken to refer to an NBAR constituent is not conclusive since one may simply be an $\mathrm{N}^{0}$ which does not subcategorize anything. For that reason it will be incompatible with a complement as depicted in (81):

(81) [EN] He met the king of Sweden and the one of Denmark

However, the Sadler and Arnold analysis is only about English formations consisting of an adjective and a noun. Crucially, they do not discuss examples such as the ones in (77) through (80).

On the analysis as a weakly lexical structure, the nominal and the complement do not form an NBAR constituent. Rather the PP for membership is a complement of the structure $\left[_{\mathrm{N} 0}\right.$ Danish application] as detailed above.

Examples such as the ones in (77) through (80) suggest that the group adjective combines with an NBAR. However, the whole cluster of syntactic and semantic properties surrounding group adjectives suggest that they are lexical and combine with an $\mathrm{N}$ to form a lexical structure. These contradictory facts remain unexplained but they may point to a general problem pertaining to the use of proforms as evidence for constituency in adjunction structures. The same phenomenon can be observed in examples with multiple adjuncts where the proform actually targets a discontinuous constituent:

(82) [DA] Peter købte en skjorte lørdag formiddag i supermarkedet og det samme gjorde Louise søndag 'Peter bought a shirt Saturday noon in the supermarket and so did Louise on Sunday' 
In (82) the proform det samme/"so" represents købte en skjorte i supermarkedet "bought a shirt in the supermarket" which, however, does not form a constituent in the preceding sentence.

To summarize: The discussion above has shown that the combinations consisting of a group adjective and a deverbal or a picture-noun form a weakly lexical structure with the properties of a lexical structure which, however, is transparent to the syntax. The failure of group adjectives to coordinate with other adjectives can be explained on semantic grounds and the problems connected to the use of proforms and NBAR-deletion may point to a general difficulty of using proforms as evidence for constituency with adjunction structures. The overall analysis corroborates the main proposal of the paper, namely that group adjectives have access to the argument structure of the head noun and modify the first argument on this list.

\section{Binding}

In Section 4.2.1 we showed that group adjectives do not pattern with arguments of nominals. We will now present further evidence that group adjectives are not some kind of nominal argument of the nouns they combine with. If group adjectives were arguments associated with external semantic functions we would expect them to participate in binding phenomena. Such expectations are not born out in general. In what follows, we discuss the data about binding.

Contrary to referential expressions (83), (84), group adjectives do not participate in binding relationships in Danish and Modern Greek (85), (86).

(83) [DA] amerikanernes opfattelse af sig selv the americans' opinion about themselves

(84) [GR] i gnomi ton Amerikanon gia ton eafto tous 'the opinion of the Americans about themselves'
[DA] $*$ ?? den amerikanske opfattelse af sig selv the american opinion about themselves
[GR] $\star_{i}$ eliniki gnomi gia ton eafto tous the greek opinion about themselves

In English, the picture is more complicated.

(87) $[\mathrm{EN}]$ the opinion of the Americans about themselves

(88) $[\mathrm{EN}] \%$ The American opinion about themselves 
(88) was rejected by some native speakers and accepted by others. Later, in Section 7.2, we attempt to provide an account of these diverse data.

The anaphors above all fall under the scope of the binding theory. It has been claimed that the ungrammaticality of the examples above is due to the fact that an adjective and an NP enter into an unsatisfiable binding relationship (Giorgi \& Longobardi 1989). Another explanation that we will pursue here is based on the assumption that binding is a (pattern matching) relationship between two entity-denoting expressions which is also embraced by HPSG. If the group adjective is property-denoting, as we are going to claim, binding can not obtain. But this in itself does not explain why group adjectives can never participate in binding relationships (actually, as we have seen, some English speakers do not share this view).

There seem to be two ways to deal with binding in NPs headed by deverbal nominals or picture-nouns.

(89) [EN] John's opinion of himself is too optimistic

(90) [EN] John maintains a too optimistic opinion of himself

In (89) the anaphor himself is bound by the subject-like argument John's. In (90), however, the anaphor is not bound within the NP but rather by the subject of the clause containing the NP John. In Pollard \& Sag (1994) this kind of binding is treated as exempt in the sense that the coindexing is not governed by syntactic factors. An alternative view that we will adopt here is that the anaphor is bound by the subject argument of the noun opinion in both cases. In (89) the subject is realized and coindexing follows straightforwardly. In (90) however, the anaphor is bound by the unexpressed subject argument of the nominal and the unexpressed subject argument, in turn, is identified with the subject of the matrix clause. Under this view an anaphor occurring as the complement of a deverbal nominal or a picture-nominal such as opinion will always be coindexed with whoever holds the opinion, and the determination of the "holder of the opinion" may be governed by non-syntactic factors. It must, however, be emphasized that the choice between these two ways of dealing with binding within the NP has no consequences for the analysis of binding in conjunction with group adjectives below. In both cases a group adjective blocks binding and this is unexpected, especially if the anaphor can be bound by an element outside the NP. Consider now the following data from Danish.

(91) [DA] en sådan opfattelse af sig selv er skadelig 'a such opinion about yourself is devastating' 
(92)

[DA] *den russiske opfattelse af sig selv er skadelig
'the russian opinion of themselves is devastating'

In (91) above the anaphor is not bound by any overt expression since there is no less oblique argument to bind it. Rather the anaphor is coindexed with the unexpressed external/subject argument of opinion since the anaphor will invariably refer to whoever holds the opinion. But the presence of the group adjective as in (92) renders the example impossible, even on the assumption that the group adjective adds restrictions to the unexpressed subject argument.

The inability of group adjectives to bind anaphors strongly suggests that group adjectives are not entity-denoting and so they can not be thematic arguments of the predicator. Furthermore, if the anaphor could be bound outside the NP or did not have to be bound at all we should expect (92) to be possible. What these data suggest is that the group adjective - apart from being a property-denoting adjunct, i.e. an adjunct which determines a type of entity (Kolliakou 1999) — adds restrictions to a special kind of unexpressed argument as compared to examples with arbitrary reference as in (91). This is further emphasized by the fact that group adjectives, as noted above, are semantically vague in the sense that they simply entail the existence of a group of people sharing some salient property such as being of the same nationality. In order to account for these puzzling facts we suggest that the first argument contains a feature which we term "воunD" (we return to this matter in Section 7.2). A predicator containing an argument with a "bound" index introduces an existential qualification: a nominal such as decision used with a group adjective entails that someone made the decision and the group adjective associates this existential qualification with the property of being say American. Note that the decision maker(s) can not be further circumscribed, i.e. the decision maker(s) may be a group or a single person and we do not know anything about the properties of this group or person apart from the fact that it may somehow be eligible for making the decision in question. A distinction between "bound" indices and other kinds of indices will furthermore allow an account of the observed cross-linguistic variation in binding by group adjectives. We will return to this point in Section 7.2.

Furthermore, the binding facts discussed thus far offer additional support to our claim that group adjectives have access to the argument structure of the head nouns. In HPSG (Manning \& Sag 1999) argument structure has been recognised as a syntactic representation level which mediates between semantics and subcategorisation, is dissociated from valency representation level and is 
suitable for accounting for binding phenomena. In particular, Manning and Sag argue that (in some languages) reflexives have to be bound by the first argument on the argument structure list rather than by the initial member of a syntactic valency list (the argument structure is represented as an ordered list). Examples discussed thus far show that group adjectives have an impact on binding phenomena involving reflexives, thus group adjectives have access to the argument structure of the head nouns they modify and, especially, to the first argument on it.

\section{Group adjectives in HPSG}

\subsection{The theoretical framework: HPSG}

As stated in the introduction we will develop an account of the empirical observations from the previous sections within the framework of HPSG. HPSG (Pollard \& Sag 1994) is a non-derivational linguistic theory which uses highly schematised rules for combining very rich lexical entries. HPSG emphasizes the need for integrating linguistic knowledge from several sources in a single representation. In the present context it means that we can simultaneously specify the syntactic and the semantic properties of group adjectives in a single representation, i.e. a lexical entry. A further benefit of choosing HPSG as the formal framework is the fact that, though being mono-stratal, HPSG allows for several distinct levels of representation. As discussed above we make a threeway distinction between valency, argument structure and semantic structure and HPSG allows for the representation of these levels while providing the means of co-indexation to represent the interaction of these various levels. In particular the architecture allows us to exploit the notion of argument structure as distinct from surface syntax and to represent the specific semantic contribution of group adjectives in a perspicuous manner. Furthermore the modelling domain of an HPSG grammar is a system of typed feature structures. The possibility of typing and of organizing types into a multiple inheritance hierarchy allows us to represent the semantic selection of nouns by group adjectives in a straight-forward manner. and to distinguish different kinds of semantic indices. In this way the grammar is able to account for the binding facts related to group adjectives discussed above.

The lexical entries in HPSG are given as constraints on feature structures which are taken to model linguistic objects which constitute the empirical 
domain of the theory. These constraints are given in the form of AttributeValue Matrices (AVMs). Legal partial descriptions of feature structures specify partial constraints on admissible lexical items. Note that two paths in a feature structure may lead to the same node, indicating token-identity of the value of two distinct attributes. Some further notation for AVMs as used in this paper: Tags appearing as subscripts refer to indices. Tags preceded by colons refer to the whole content. Sets are indicated with curly brackets and lists in angle brackets, where \langle\rangle indicates the empty list.

In the following we will present a lexical entry for a group adjective. Furthermore we will develop the type partitions for semantic indices and the content of nominals.

\subsection{The proposal}

\subsubsection{Group adjectives and levels of valency saturation}

As noted in Section 2 group adjectives have access to a dimension of lexical information that determines valency saturation. Three such levels are distinguished: (a) the semantic level (b) the subcategorisation level and (c) the argument structure. In HPSG these levels are represented as the CONTENT, the VALency lists and the ARG_s respectively. Bouma, Malouf \& Sag (1998) propose a third level of syntactic dependency structure (apart from argument structure and subcategorisation) which they term DEPENDENTs (DEPS). The list of dependents contains all the items that a predicator combines with locally and non-locally, i.e. an extracted complement is present on the DEPs list but not on the COMPs list. The DEPs list is crucial for the analysis of extraction developed in Bouma, Malouf \& Sag (1998) but it has no impact on the account of group adjectives developed here. For ease of exposition we will ignore the DEPs list in our representations. We will return to the treatment of adjunction in Bouma, Malouf \& Sag (1998) below.

In the following we will argue that group adjectives apply to the argument structure list and not to the subcategorization level or the semantic level. An account relying on the semantic level would ignore the facts pointed out in Section 2.2. There, we had shown that a group adjective is always related to the subject argument of the active verb predicate the adjective is related with. This fact already sets the problem on syntactic rather than semantic grounds. On the other hand, an account relying on the subcategorisation level would entail that group adjectives are just like other thematic arguments which normally saturate subcategorisation requirements, namely that they are entity-denoting expressions. 
In Sections 4.2.1 and 6, we have presented strong evidence that group adjectives are not entity-denoting expressions and that the appropriate level of representation to which group adjectives apply is the so-called argument structure. This is a syntactic level of information mediating the mapping from lexical semantics to subcategorisation. In HPSG, argument structure is represented as a list containing nominal or verbal arguments. This list stands for an ordered set, that is, its arguments are ordered and unique. Argument structure can provide the desired generalisations which can not be expressed with lexical semantics because, in different nominals, different semantic cases may be mapped on the same argument structure argument. To give a somehow simplified example, when a transitive nominal has both an agent and a theme semantic argument, the agent will map on the first argument of the argument structure and the theme on the second. When a nominal has a theme semantic argument only, it will map on the single argument of the argument structure list.

In Section 2.2, we have seen that the distribution of group adjectives is ruled by two syntactic constraints:

1. group adjectives can be related only with the subject of the verb predicate derivationally related with the head noun

2. group adjectives appear only with nominals which can support DPs in the genitive case while these DPs are interpreted as the subject of the verb predicate derivationally related with the head noun

Therefore, the representation proposed should enable the argument structure of the deverbal nominal to have access to the argument structure of the basic lexeme (the parent verbal predicate). In their account of passivization Manning \& Sag (1999) assume that passive verbs contain nested argument structures. A passive verb inherits the arguments of the active verb but the argument structure of the active verb is preserved in the argument structure of the passive verbs. The arguments of the derived lexeme are related to their original position in the argument structure of the basic lexeme through place holders (coindexed PROs). In this way an argument may (but need not) obey different prominence relations determined by the position of the argument in the argument structure of the derived and the basic lexeme, respectively.

Furthermore, by adopting this proposal for the derivation of nominals, Alexiadou's (Alexiadou 2001) proposal that all deverbal nominals have an argument structure can be straightforwardly represented in HPSG. The argument structure of the verb predicate (which is embedded in the nominal) has as its first argument the subject argument of the predicate. Thus, we require 
that group adjectives combine with deverbal nominals where the first argument on the nominal's argument structure is co-indexed with the first argument on the embedded verbal argument structure. Argument structure offers the necessary syntactic information which captures the two syntactic constraints ruling the distribution of group adjectives. The argument structure of a nominal which may be selected by a group adjective thus takes the format shown in Figure 1 (ignoring for present purposes other arguments than the subject argument).

$$
\text { ARG_S } \left.\left\langle\text { NP }[\text { INDEX] }],\left\langle\operatorname{PRO}_{[1} \ldots .\right\rangle\right\rangle\right\rangle
$$

Figure 1. Nested Argument Structure

One last word is due here concerning the fact that group adjectives have a preference for the first element in the ARG_s only. Given that group adjectives are not referential expressions, one could argue that they cannot combine with the second or other argument of the ARG_s because these elements have to be referential in order to support the overall aspectual structure of a complex event nominal. On the other hand, simple event/result nominals do not support "internal" syntactic arguments.

\subsubsection{A hierarchy of nominal objects}

In order to account for the fact that group adjectives only combine with deverbal nominals and for the fact that there is cross-linguistic variation in the semantic type of the deverbal nominals we propose a partitioning of nomobj as shown in Figure 2. This partitioning is independently motivated because deverbal nominals admit special modification, eg. by adverbials and enter into special syntactic structures. The partitioning follows the classification of nominals in Grimshaw (1990).

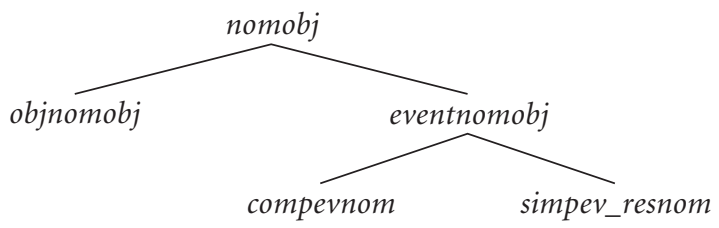

Figure 2. Partitioning of nomobj 
nomobj (nominal objects) partition into into objnomobj (object nominal objects) and eventnomobj (event nominal objects). eventnomobj in turn is partitioned into compernom (complex event nominals) and simpev/resnom (simple event nominals and result nominals).

Nouns other than deverbal ones have content of type objnomobj. Adjectives other than group adjectives select for nominals with a content of type nomobj. All types of adjectives have contents of type nomobj. This fact accounts for the following data:

(93) $[\mathrm{EN}]$ the wise decision

(94) $[\mathrm{EN}]$ the wise American decision

(95) [EN] *the American wise decision

Since Greek group adjectives do not combine with complex event nominals, they select for nominals of type simpev/resnom while the corresponding Danish or English adjective would select for nominals of type eventnomobj. Here, we remind the reader of the fact that this situation with Greek can be explained on purely syntactic grounds, namely that the Modern Greek NP can contain only one "free" NP in the genitive case (Horrocks \& Stavrou 1983).

\subsubsection{Nominal indices: The feature BOUND}

We will now introduce a modification of index which accounts for uniqueness and binding phenomena discussed in Sections 2 and 6. Bound takes values of type bound with the partitioning shown in Figure 3.

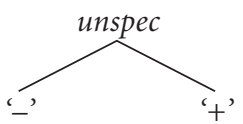

Figure 3. Partitioning of the feature BOUND

Referential expressions such as NP arguments of predicators and reflexive anaphors have indices with value of feature Bound -. Argument structure arguments which are not referential have Bound value + . These arguments do not map on valency lists, i.e. they remain unexpressed but are syntactically active in the sense that they may e.g. license modifiers such as group adjectives. We will return to a more elaborate discussion of how this modification of index accounts for the observed data below. In contrast to the proposed partitioning of nominal objects the feature Bound is not independently motivated. It must, however, remain a matter of further investigation to determine whether the 
category of non-referential thematic arguments is reflected in other parts of the syntax as well.

\subsubsection{Lexical entries for group adjectives}

Consider the lexical entry for the Greek group adjective eliniki "greek".

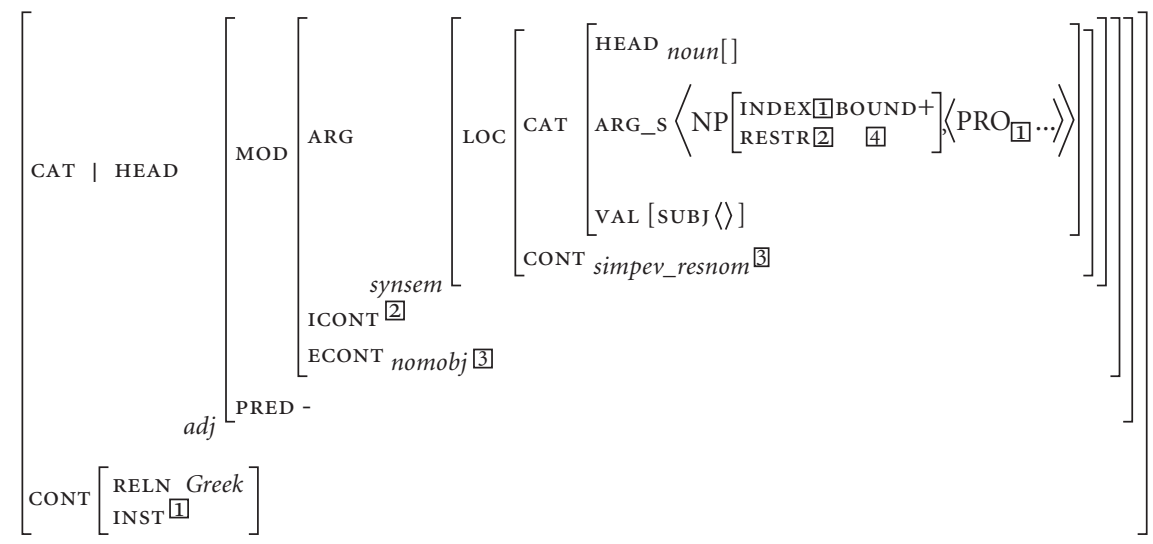

Figure 4. Lexical entry for the Greek group adjective eliniki "greek"

Compared to a restrictive adjective such as red there are two important things to note about this lexical entry: the semantic contribution of the group adjective and the selection of a head nominal with a particular semantics.

A restrictive adjective adds a restriction to the index of the selected head nominal. In contrast to this, the group adjective adds a restriction to the first element on the argument structure of the head noun. As an illustration consider the derivation of the N eliniki apofasi "greek decision" shown in Figure 5.

In this derivation the adjective has combined with a nominal head. By virtue of Kaspers revised Semantics Principle the content of the resulting phrase is structure shared with the external content (ECONT) of the adjunct daughter. The adjunct daughter's CONTENT in turn, is structure-shared with the ICONT-value of the adjunct daughter's MOD-feature.

In contrast to intersective adjectives such as red the semantic contribution of the group adjective is not immediately to be read off the projected semantics of the phrase. The index of the ARG_1 however, is structure-shared with the index of the first argument of the predicate which, in turn, carries the restriction that it is greek. The contribution of the group adjective would figure in the projected semantics of the phrase by adopting a version of Minimal Recursion 


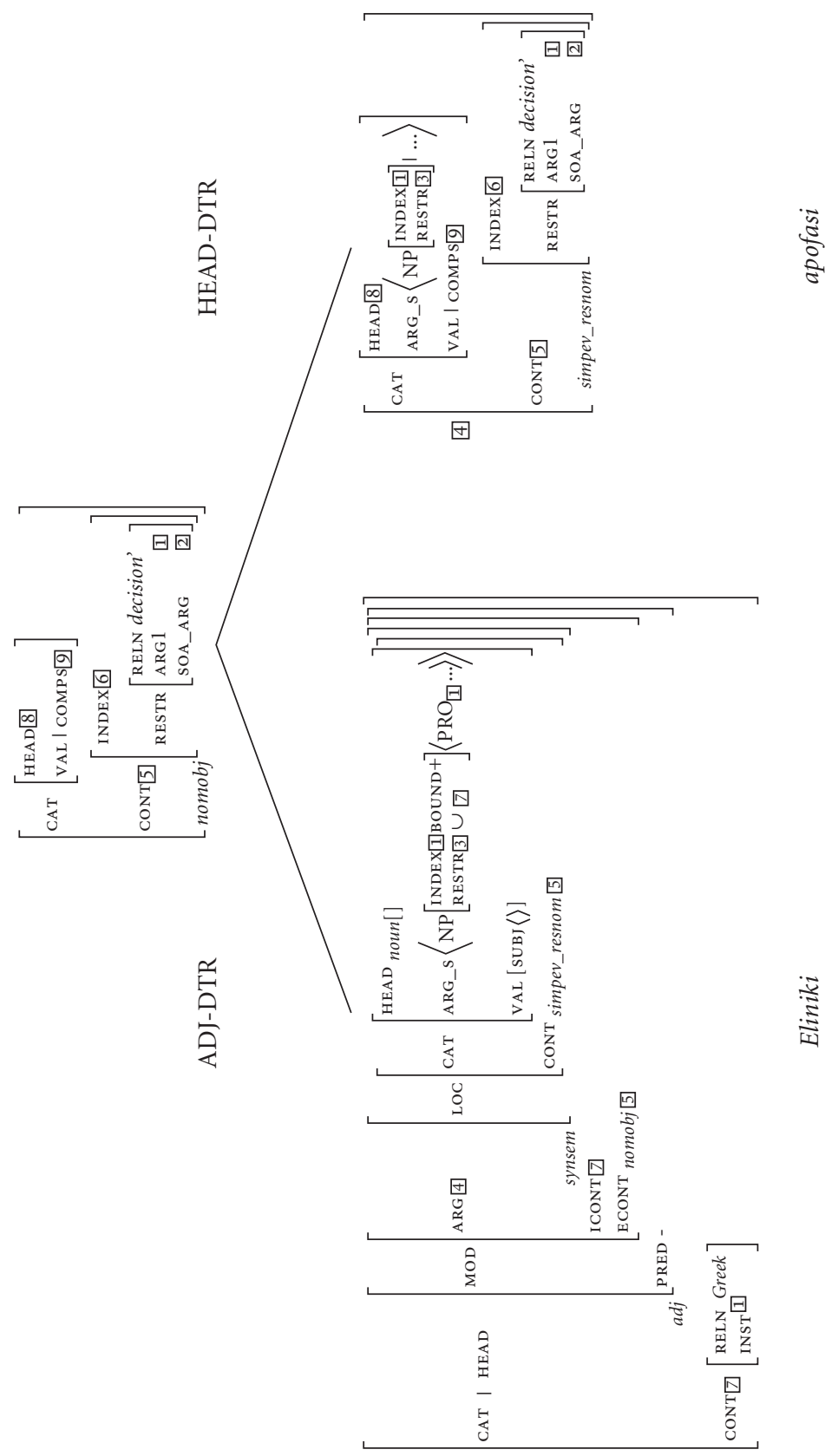

Figure 5. Derivation of the construct eliniki apofasi "greek decision" 
Semantics as in Sag \& Wasow (1999) or the approach in Mueller (1999) where the projected phrase is associated with the attribute CONTEXTIINDs where all indices of arguments along with their restrictions are collected and projected to the mother node.

As noted in Sadler \& Arnold (1994) an XBAR-oriented theory such as HPSG does not embrace structures which are neither fully lexical nor fully phrasal. For this reason the particular weakly lexical structure of Arnold \& Sadler (1994) is not formally represented in the derivation but needs to be developed.

\subsubsection{Accounting for the data}

Lets us finally discuss how the lexical entry for the group adjective accounts for the two crucial questions posed in the analysis above: why does an adjective seemingly occupy an argument position? how do we account for cross-linguistic variation in the binding behaviour of group adjectives?

Group adjectives in all the three languages under consideration select for head nouns associated with an argument structure list whose first member is an argument associated with an index containing the description Bound: +. This makes sure that no referential expression will realise the first ARG_s argument in the syntax once the head noun has combined with the group adjective. For instance, no prenominal genitive or of-PP phrase in English nor a DP marked with the genitive case in Greek will be coindexed with the first ARG_s argument. Such "referential" expressions are incompatible with the specifications on the first ARG_s argument because they have indices with the description BOUND:-. In this way, uniqueness phenomena are accounted for in the sense that the examples below are possible only on a qualitative reading of the adjectives in question (96), (97).

(96) [EN] *the germans' german answer

(97) [EN] *the german answer of the Germans

The description BOUND: + on the first ARG_S argument of the deverbal noun also accounts for the binding phenomena we discussed in Section 6. We assume that for all the speakers of Danish and Modern Greek, who reject phrases where an overt anaphor is bound by a group adjective, overt reflexives have indices with the description Bound: - . As we have seen in Section 6, English presents a more complicated picture in that some speakers do not allow for binding of an overt reflexive by a group adjective but other speakers do (98).

(98) $[\mathrm{EN}]$ \%the english opinion about themselves $_{\mathrm{i}}$ 
We thus suggest that the native speakers of English who find (98) well-formed have overt reflexives with the description Bound: unspec. unspec can be coindexed with both ' + ' and '-' values because it is a more general type.

\section{Conclusion}

In this paper, we have studied group adjectives in three languages, namely Danish, English and Modern Greek. We have found that group adjectives present a strikingly similar behaviour across this set of languages. In particular, we have presented evidence which shows that

1. group adjectives combine with both event and result denoting nominals

2. group adjectives and nouns form weakly lexical structures which are not opaque to the syntax; this is manifested, among others, with uniqueness and binding phenomena

3. group adjectives select their head nouns on purely syntactic grounds; in particular, they have access to the argument structure of their head nouns and modify the first argument on this list on the condition that the latter is coindexed with the first argument on the argument structure of the parent verbal predicate. This explains the distributional facts including the canonical agentive interpretation of group adjectives.

Our study gives ARG_s a role in modification phenomena which leads us directly to valency saturation phenomena and suggests that ARG_s plays a role in this direction. In this way, ARG_S is further dissociated from the syntactic valency representation level.

\section{Notes}

* We have presented this research at the 3rd International Conference on Greek Linguistics, 1997, the LAGB Spring Meeting, and the Workshop Modern Greek in the Light of Contemporary Syntactic Frameworks which was held at the Department of Linguistics, University of Thessaloniki, Friday 29th of January, 1999. We would like to thank the audiences for their questions and contributions. We would also like to thank Den danske Ordbog for letting us use their corpora for a search on Danish group adjectives. Special thanks are due to Elisabeth Engdahl and Carl Vikner for comments on an earlier version of this paper.

1. To indicate the language we derive an example from, we prefix one of the following abbreviations: DA(nish), EN(glish) and GR(eek). In the examples, all group adjectives are 
spelled with a lower case first letter. We adopt this spelling convention in order to emphasize that it is the meaning and the syntactic function that sets group adjective readings apart from qualitative ones.

2. There are, however, counter examples to the claim that group adjectives do not occur predicatively. Cf. this example from Modern Greek:

[ILSP CORPUS 219060]

Gia to thema ton Imion i protasi gia prosfigi sto Dikastirio tis Hagis ine eliniki?

"Is the proposal for appealing to the Court of The Hague for the issue of Imia greek?"

This is in fact an example of spoken Modern Greek. It is a question addressed to the Minister of Foreign Affairs during a briefing about the situation with Imia. However, we have not been able to detect any other such examples in the Corpus. It seems that in contrastive or interrogative contexts a predicative use of the adjective is not completely excluded.

3. However, corpus search has shown that such structures do occur especially in the newspaper register of Modern Greek.

\section{ILSP CORPUS 981898}

Ftei arage gi afto i gnosti amerikaniki ipotimisi tou paragonta EE

"Could the well-known american underestimation of the EU factor be blamed for that"

\section{ILSP CORPUS 54036}

Afti i fetini amerikaniki dierevnisi tou thematos den prokite na ine ke i teleftea "This year's american investigation of the issue is not going to be the last one."

4. Sag \& Godard (1994) assume that simple nominals such as house are also equipped with an argument structure. The behaviour of group adjectives, however, seems to suggest that simple nominals such as house should be treated differently from the nominals traditionally discussed in conjunction with binding within NPs. When the adjective occurs with a simple noun as in (i) below it predicates a quality of the head noun:

(i) the Venetian houses

Admittedly the adjective in (i) can also be interpreted as agent-like: the houses built by the Venetians. It may, however, also be interpreted as the houses in Venice or the houses built in a Venetian style. Group adjectives, i.e. group adjectives occurring with deverbal or picturenominals do not allow the same range of interpretations. Furthermore, the same readings are available for Venetian occurring in postcopular positions as in (ii)

(ii) the houses are Venetian

For these reasons we believe that Venetian in this use is not a group adjective. This, in turn, may be attributed to the fact that houses does not have an argument structure to license a group adjective. 
5. A Reviewer points out that constructs like

Mikrasiatiki Katastrofi

Asia Minor Destruction

Evropaiki Enosi

European Union

are well-attested in Modern Greek. These examples are clearly compounds, the first one naming an important historical event, the second one an international constellation. Their meaning is not compositional and no theme or agent or location or other interpretation is available for the relational adjective in either case.

6. Further evidence in favour of the argument structure approach comes from the analysis of extraction from the French NP in Godard (1992). Godard assumes that only the syntactically identified first argument of the argument structure may be extracted. Thus a themeargument of a nominalisation with two arguments can only be extracted if the more prominent argument, typically the agent-argument is suppressed. In the presence of a group adjective, which identifies an agent, a theme argument can not be extracted. On these grounds Godard assumes that the adjective is linked to the first argument. In the presence of a $c$-phrase realizing the agent, a theme argument may be extracted since a par /' "by" -phrase is not the first argument in the argument structure list but rather a more oblique argument. Cf. the following examples from Godard (1992), p. 269:

(i) Ils voulaient obtenir une modification des montants compensatoires, dont le refus allemand a bloqué les négociations

"they wanted to obtain a modification of the compensatory amounts, of-which the German refusal stopped the negotiations"

(ii) ...dont le refus par les Allemands a bloqué les négociations ...of-which the refusal by the Germans stopped the negotiations

In order to account for these data, Godard (1992) makes a distinction between suppression of an argument and downgrading of an argument. In (i) the adjective is linked to a suppressed argument which is not downgraded while the par l' "by" -phrase in (ii) is linked to a suppressed and downgraded argument. In this way, Godard associates the groupadjective with a "non-canonical" first argument (in terms of saturation abilities) and she establishes a distinction between this kind of arguments and par /" "by" -phrases. Pursuing a similar idea, we consider this non-canonical first argument to be an argument which is unable to be syntactically realised by a referential NP-expression in our effort to explain a host of facts concerning group adjectives such as uniqueness, binding and control phenomena (Kolliakou 1999), however, presents a alternative account of extraction from NPs in French whereby extraction is not related to argument structure but rather to interpretive notions.

7. The coordination of group adjectives is subject to subtle restrictions which seem to vary across the three languages under consideration. In Danish group adjectives may coordinate to give distributive readings, but never collective readings. In English group adjectives may coordinate to give both collective and distributive readings. In Greek, group adjectives can coordinate when they combine with a simple event denoting noun. 
In Danish group adjectives can not coordinate syndetically to yield collective readings in contrast to NP complements.
(3) a. [DA $]$ danskernes og tyskernes beslutning the Danes and the Germans decision
b. [DA] den danske og tyske beslutning the Danish and German decision

The example in (3a) is ambiguous between a reading in which there are two decisions: one made by the Danes and one made by the Germans, and one decision made by the Danes and the Germans in consonance. In (3b) only the distributive reading with two decisions (which may have the same content) is possible. The only way to yield a collective interpretation is by means of an exocentric compound as shown in (4):

(4) $[\mathrm{DA}]$ den dansk-tyske beslutning the danish-german decision

We may hypothesize that group adjectives denote disjoint sets and so can not apply to one single entity, but intersective adjectives such as colour adjectives can coordinate syndetically to denote a complex property:
(5) a. [DA $]$ den røde og hvide bil
the red and white car
b. [DA] den rød-hvide bil
the red-white car

Example (5a) is ambiguous between a reading with two cars of different colour, and one car which is partly red and partly white. If group adjectives fail to coordinate because they denote disjoint sets we are still left to explain why colour adjectives which are also taken to denote disjoint sets can coordinate syndetically to denote a complex property.

In Greek, group adjectives combining with result nouns can not coordinate at all as illustrated in (6a) below. Rather the group adjectives pattern with nominal complements in always requiring the presence of the article in the second conjunct as shown in (6b) and (6d) even though (6b) is still marginal. Example (6b) with the group adjective, however, only allows for a distributive reading while the version with NP complements has a preferred collective reading.

(6) a. [GR] ${ }^{*_{i}}$ daniki ke germaniki apofasi the danish and german decision

b. [GR] ??i daniki ke i germaniki apofasi the danish and the german decision

c. $[\mathrm{GR}]{ }^{*_{i}}$ apofasi ton Danon ke Germanon the decision of the Danes and Germans

d. $[\mathrm{GR}] \mathrm{i}$ apofasi ton Danonke ton Germanon the decision of the Danes and of the Germans

With result nominals, a collective reading of group adjectives is only possible by means of an exocentric compound: 
(7) $[\mathrm{GR}]$ i danogermaniki apofasi

the danish-german decision

In this respect, group adjectives pattern with colour adjectives which do not seem to coordinate in conjunction with definite NPs:

(8) a. [GR ${ }^{\star ? ?}$ to aspro ke mavro gati the black and white kitten

b. [GR] to aspromavro gati

the black-white kitten

However, corpus study has revealed that a collective reading is occasionally possible.

(9) [GR][ILSP CORPUS 1161725]

proevlepe metaksi alon tin paremvoli irineftikis dinamis, me rosiki kai tourkiki simetohi

"required inter alia the insertion of peacemaking power with russian and turkish participation”

In English again, the picture is different. According to our informants, coordinated group adjectives in conjunction with a singular head noun yield a collective reading, while coordinated group adjectives in conjunction with a plural head noun yield a distributive reading as the preferred one.

(9) a. $[\mathrm{EN}]$ the danish and german decision

b. $[\mathrm{EN}]$ the danish and german decisions

These differences between the three languages is unexpected given that group adjectives otherwise behave strikingly alike in the languages under study. These issues await further study.

\section{References}

Alexiadou, A. \& M. Stavrou. 1998. “On Derived Nominals in Greek”., Themes in Greek Linguistics II, ed. by B.D. Joseph, G.C. Horrocks and I. Philippaki-Warburton, Volume 159 of Current Issues in Linguistic Theory, 101-129. Amsterdam/Philadelphia: John Benjamins Publishing Company.

Anastasiadi-Simeonidi, A. 1986. Neologism in Modern Greek. PhD thesis. Thessaloniki.

Alexiadou, A. 2001. Functional Structures in Nominals. Nominalisation and ergativity. Amsterdam/Philadelphia.

Bouma, G. \& R. Malouf \& I. A. Sag. 1998. "A Unified Theory of Complement, Adjunct, and Subject Extraction." Proceedings of the FHC98 Symposium on Unbounded Dependencies, ed. by G. Bouma, G.-J.M. Kruijff and R. T. Oehrle, R. T., 83-97. Saarbrücken. Universität des Saarlandes und DFKI. 
Bouvier, Y.-F. 2000. Definir les composes par opposition aux syntagmes. Generative Grammar in Geneva 1.

Chomsky, N. 1970. "Remarks on Nominalisation". In R. Jacobs and P. Rosenbaum (eds) Readings in English Transformational Grammar. Waltham, Mass.: Ginn and Company: 184-221.

Giannakidou, A. \& M. Stavrou. 1999. "Nominalization and ellipsis in the Greek DP”. The Linguistic Review, 16: 295-331.

Giorgi, A. \& G. Longobardi. 1989. "Typology and Noun Phrases". Rivista di Linguistica, 1: $115-161$.

Giorgi, A. \& G. Longobardi. 1991. The Syntax of Noun Phrases. Cambridge Studies in linguistics. Cambridge: Cambridge University Press.

Godard, G. 1992. "Extraction out of NP in French”., Natural Language \& Linguistic Theory, 10: 233-277.

Grimshaw, J. 1990. Argument Structure. Volume 18 of Linguistic Inquiry Monographs. MIT.

Horrocks, G. \& M. Stavrou. 1987. "Bounding Theory and Greek Syntax: Evidence for wh-movement in NP”. Journal of Linguistics, 23: 79-108.

Kayne, R. S. 1984. Connectedness and Binary Branching. Dordrecht: Foris Publications.

Kolliakou, D. 1999. "De-Phrase Extractability and Individual/Property Denotation”. Natural Language and Linguistic Theory, 17: 713-781.

Levi, J. N. 1978. The Syntax and Semantics of Complex Nominals. New York: Academic Press. Manning, C. \& I. Sag. 1999. "Dissociations between Argument Structure and Grammatical Relations”., Lexical dnd Constructional Aspects of Linguistic Explanation. Stanford: CSLI Publications.

Markantonatou, S. 1995. “Modern Greek Deverbal Nominals: an LMT Approach”. Journal of Linguistics, 31: 267-299.

Müller, S. 1999. Deutsche Syntax deklarativ. Number 394 in Linguistische Arbeiten. Niemeyer.

Ørsnes, B. 1995. The Derivation and Compounding of Complex Event Nominals in Modern Danish - an HPSG Approach with an implementation in Prolog. PhD thesis, University of Copenhagen.

Pollard, C. \& I.A. Sag. 1994. Head-Driven Phrase Structure Grammar. Chicago: Chicago University Press.

Ralli A. \& M. Stavrou. 1998. "Morphology-Syntax Interface: A-N compounds vs. A-N Constructs in Modern Greek"., Yearbook of Morphology 1997, ed. by I. G. Booij and J. van Marle, pages 243-264. John Benjamins Publishing Company. Kluwer Academic Publishes.

Sadler, L. \& D. Arnold. 1994. "Prenominal Adjectives and the Phrasal/Lexcial Distinction". Journal of Linguistics, 30: 187-226.

Sag, I. \& T. Wasow. 1999. Syntactic Theory: A Formal Introduction. CSLI Publications.

Sag, I. \& D. Godard. 1994. "Extraction of de-Phrases from the French NP"., NELS 24, pages 519-541. University of Masachusetts, Amherst, GLSA.

Selkirk, E. O. 1982. The Syntax of Words, Volume 7 of Linguistic Inquiry Monograph. Cambridge, Massachusetts, London, England: The MIT Press.

Toivonen, I. 2001. The Phrase-Structure of Non-Projecting Words. PhD thesis. Stanford University. 


\section{$\Pi \varepsilon \rho \dot{\lambda} \lambda \psi \eta$}

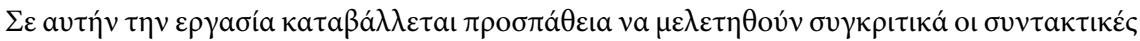

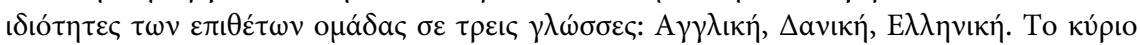

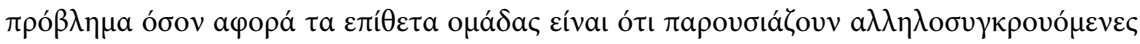

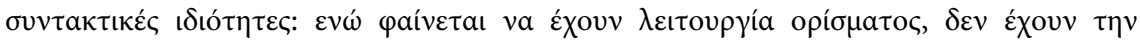

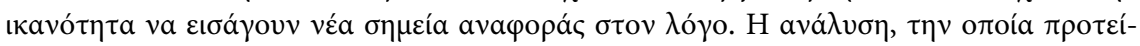

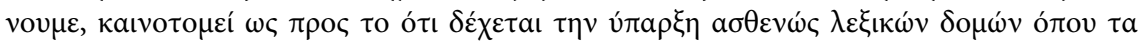

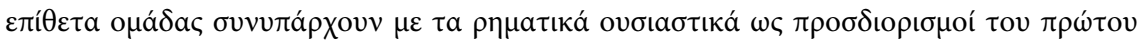

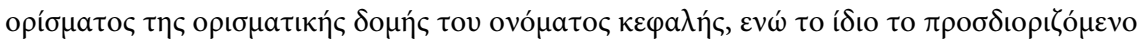

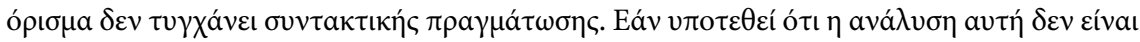

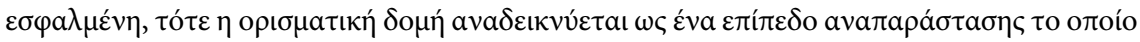

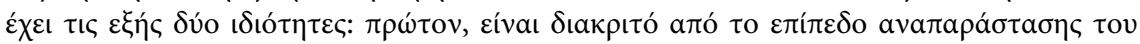

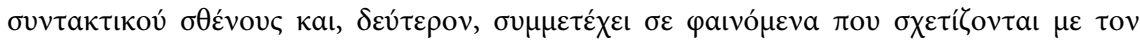

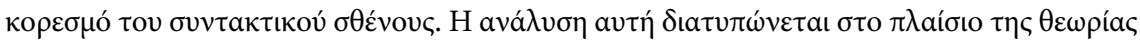

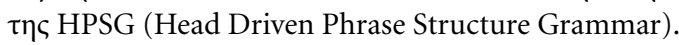

